\title{
ПЕРСПЕКТИВА ПРИМЕНЕНИЯ ВЕЩЕСТВ АНТИКВОРУМА КАК АЛЬТЕРНАТИВА АНТИБИОТИКОТЕРАПИИ В ЖИВОТНОВОДСТВЕ
} (обзор)

\author{
К.С. КОНДРАШОВА ${ }^{凶}$, Д.Б. КОСЯН, К.Н. АТЛАНДЕРОВА, С.В. ЛЕБЕДЕВ
}

Частое применение антибиотиков в современном животноводстве грозит расширением спектра антибиотикорезестентных бактерий. Один из механизмов, ответственных за этот процесс, - кворум сенсинг (Quorum sensing, QS). Для его реализации бактерии используют специальные сигнальные молекулы для обмена информацией - аутоиндукторы (А.A. Miller с coaвт., 2011). Благодаря изучению описываемого механизма стало известно о существовании веществ, выступающих в роли ингибиторов Quorum sensing (гасители кворума) (В. Remy с соавт., 2018), что сделало такие исследования еще более актуальными (J. Bzdreng с соавт., 2017). В своем обзоре мы обобщили современные данные о поиске и разработке таких биологически активных соединений, способных стать альтернативой антибиотическим препаратам, применяемым в сельском хозяйстве. Среди них можно выделить бактериальные ферменты (АГЛ-лактоназы, АГЛацилазы, декарбоксилазы и дезаминазы), способные деградировать сигнальные аутоиндукторы кворум сенсинга (V.C. Kalia с соавт., 2011), а также $\alpha$-амилазы, $\beta$-глюканазы, липазы и протеазы, способствующие разрушению биопленки (R. Sharma с соавт., 2001). Антимикробными свойствами также обладают ферменты животных - ацилаза I (D. Paul c соавт., 2010), параоксоназа (J.F. Teiber с соавт., 2008), лактоназа; ферменты растений - лакказа (R. Al-Hussaini с соавт., 2009), аллииназа, тиолзависимый фермент и лактоназа, выделенные из чеснока и лекарственных растений (A. Adonizio с соавт., 2008); ферменты морских организмов - бромопероксидаза из водорослей Laminaria digitata (а также галогенированные фураноны из Delisea pulchra) и альгинатные лиазы, обнаруженные в водорослях, беспозвоночных и морских микроорганизмах (S.A. Borchardt с соавт., 2001; М. Manefield с соавт., 2000). Можно также отметить антимикробные пищеварительные ферменты, используемые в качестве кормовых добавок, - фитазу (O. Adeola с соавт., 2011), ксиланазу и лизоцим (G. Cheng с соавт., 2014). Перспективными представляются исследования фитобиотиков и эфирных масел в качестве ингибиторов кворум сенсинга (В.И. Фисинин с соавт., 2018). Их ингибирующая способность проявляется благодаря сходству химической структуры некоторых растительных экстрактов и ацил-гомосерин-лактона и инактивации сигнальных молекул (R. Chevrot с соавт., 2006; F. Nazzaro с соавт., 2013). Кроме того, в качестве альтернативы рассматривается комбинированное воздействие антимикробных препаратов, которое способно дать синергетический эффект за счет разнообразия механизмов, необходимых для преодоления рецидивирующей бактериальной коммуникации и уничтожения персистирующих клеток. В состав таких полипрепаратных коктейлей может включаться сочетания антибиотиков с природными соединениями. Показана эффективность комбинации тобрамицина и некоторых растительных экстрактов (циннамальдегида и гидрата байкалина) против Burkholderia cenocepacia и Pseudomonas aeruginos (G. Brackman с соавт., 2011), широкого спектра антибиотиков - аминогликозидов (T.H. Jakobsen с соавт., 2012; M. Stenvang с соавт., 2016), хинолонов (Q. Guо с соавт., 2016), полипептидных антибиотиков (А. Furiga с соавт., 2016; Z.P. Bulman с соавт., 2017), цефалоспоринов и гликопептидов (D. Maura с соавт., 2017) и различных ингибиторов кворум сенсинга.

Ключевые слова: кворум сенсинг, антибиотки, резистентность, бактерии, растительные экстракты, ферменты.

Открытие и применение антибиотиков играет беспрецедентную роль в решении многих проблем, связанных с профилактикой, контролем и лечением инфекционных заболеваний животных (1). Помимо этого, использование антибиотиков в кормах служит важным фактором увеличения их эффективности, стимулирования роста и улучшения качества продуктов животного происхождения. Однако, несмотря на все преимущества применения антибиотиков, их чрезмерное использование привело к появлению и увеличению числа резистентных микроорганизмов (2, 3). Применение антибиотиков в сельском хозяйстве не только вызывает устойчи-

\footnotetext{
* Исследования выполнены в соответствии с планом НИР на 2019-2021 годы ФГБНУ ФНЦ БСТ РАН в
} рамках тематического плана по госзаданию № 0526-2019-0002. 
вость у микрофлоры животных, но и изменяет состав и свойства микрофлоры в природных местах обитания (почвы, подземные воды) в сторону увеличения антибиотикоустойчивости микробного сообщества (4). По этой причине в 1986 году Швеция впервые ввела запрет на использование некоторых антибиотиков в кормах животных (5). В 2006 году страны Европейского союза ввели запрет на антибиотики - стимуляторы роста в соответствии с постановлением Европейского парламента и Совета ЕС № 1831/2003 от 22.09.2003, что, однако, стало причиной негативных последствий для животноводства из-за роста числа инфекций среди поголовья. Это привело к необходимости не только вновь использовать антибиотики, но и увеличить объемы их применения (3, 6-8). На территории России запреты на применение кормовых антибиотиков отсутствуют, разрешены тетрациклины (биотин на основе продуцента хлортетрациклина), гризин, бацитрацин (бихилицин), тилозин. Единственное ограничение состоит в том, что антибиотики необходимо исключить из рациона за 5 сут-3 нед до убоя (9). Правительство России в распоряжении № 604-р от 30.03.2019 утвердило план мероприятий по реализации Стратегий предупреждения распространения антимикробной резистентности.

Резистентность у бактерий контролируется набором механизмов, позволяющих избежать воздействия антибиотиков. Она может быть либо врожденной (отсутствие мишени для антибиотика или ее недоступность) (10) или приобретенной в результате переноса генов из соседнего организма (11-13), либо возникнуть благодаря повышенной частоте мутаций (14-16), либо проявиться как адаптивная экологически индуцированная резистентность (17). Также инактивация антибиотика может происходить за счет бактериальной модификации фермента или при участии деградирующего фермента, который изменяет мишень антибиотика (18-22). В то же время бактерии могут изменять проницаемость своей клеточной стенки для оттока антибиотиков за пределы клетки с помощью эффлюксного насоса (23-25). Скорость выведения обычно выше, чем скорость проникновения лекарственного средства, тем самым контролируется уровень антибиотиков в клетке $(26,27)$. Американское общество инфекционных болезней выделило группу микроорганизмов, способных «ускользать» от антибактериального действия антибиотиков, осуществляемого по описанным механизмам, - Staphylococcus aureus, Enterococcus faecium, Klebsiella pneumoniae, Pseudomonas aeruginosa, Acinetobacter baumannii и Enterobacter. Эти виды представляют собой новую парадигму инвирулентности, трансмиссии и устойчивости к противомикробным препаратам (28).

Помимо этого, бактериальные сообщества формируют резистентность благодаря процессу, известному как кворум сенсинг (quorum sensing, QS), который мы рассмотрим в качестве основного механизма в этом обзоре. Его суть заключается в том, что микроорганизмы производят аутоиндукторы (AI), которые действуют как межклеточная сигнализация для контроля плотности популяции и координации ее деятельности, в том числе формирования биопленки, проявления вирулентность, размножения, образования спор и горизонтального переноса генов (29). Внутри биопленки бактерии примерно в 1000 раз устойчивее к антибиотикам, чем их планктонные предшественники $(8,30)$.

Активные вещества, подавляющие QS, называются ингибиторами кворума (QSI). В отличие от широко используемых в настоящее время антибиотиков эти агенты уменьшают количество микробных инфекций, подавляя индукцию микробного QS, причем, как правило, они не влияют на рост бактерий $(31,32)$. Поскольку QS индуцирует различные вредные при- 
знаки, то нарушение коммуникации бактерий представляется перспективным во многих областях, особенно в здравоохранении и сельском хозяйстве $(33,34)$

Кворум сенсинг как механизм коммуникации бакте р и й. Кворум сенсинг - особый тип регуляции экспрессии генов бактерий, функционирующий в условиях критически высокой плотности их популяции (35). Этот молекулярный механизм необходим микроорганизмам для того, чтобы они коллективно адаптировали свое поведение в соответствии с плотностью клеточной популяции и условиями окружающей среды. Эта система коммуникации позволяет бактериям осуществлять процессы, которые затратны и неэффективны при низкой плотности клеток, но становятся полезными для всего сообщества при высокой плотности клеток (продукция фактора вирулентности, формирование биопленок, а также синтез протеаз и сидерофоров) (36).

Система QS была обнаружена и описана как у грамположительных, так и у грамотрицательных бактерий. У грамположительных микроорганизмов широко изучались аутоиндуцирующие пептиды (AIP), аутоиндуктор-2 (AI-2) и другие сигнальные молекулы, такие как хинолоны, сложные эфиры и жирные кислоты, которые вызывают QS. Эти пептиды видо- и штаммоспецифичны и были описаны у Staphylococcus spp., Clostridium spp., Enterococcus spp. и других штаммов (37).

У грамотрицательных бактерий, таких как Pseudomonas spp., Acinetobacter spp. и Burkholderia spp., описан другой класс аутоиндукторов ацил-гомосерин-лактоны (АГЛ) (38). Эти соединения состоят из лактонового кольца и алифатической ацильной цепи разной длины и с разнообразными модификациями (38). Большинство грамотрицательных бактерий сочетают несколько систем QS для интеграции различных сигналов либо обладают иерархической системой: например, у Pseudomonas aeruginosa она объединяет четыре системы QS (las, rhl, iqs и pqs), действующие в сети (39), тогда как в параллельной иерархической системе Vibrio harveyi три системы интегрированы в один регуляторный каскад (40).

Также были идентифицированы другие типы сигнальных молекул (41), включая жирные кислоты, используемые Xanthomonas spp., Burkholderia spp., Xylella spp. (42), кетоны у Vibrio spp., Legionella spp. (43), адреналин, норэпинефрин, AI-3 у энтерогеморрагических бактерий (44) и хинолоны у Pseudomonas aeruginosa (45). AI-2 (диэфир фуранозилбората) используется как грамотрицательными, так и грамположительными бактериями (46).

Характеристика веществ, подавляющих кворум сенсинг. Процесс, препятствующий коммуникации бактерий, известный как ингибирование QS (QQ), имеет огромное значение для проблемы бактериальной резистентности. Он был открыт как естественное явление, впервые описанное в 2000 году, с идентификацией фермента QQ, способного деградировать сигналы АГЛ Erwinia carotovora (47) при ферментативном гидролизе.

B системе QS синтез сигнальных молекул играет жизненно важную роль в коммуникации между клетками (48). Бактериальная коммуникация может нарушаться посредством нескольких процессов.

Подавление синтеза сигнальных молекул с помощью QSI - прямой способ нарушить QS. Если сигнальные молекулы не производятся, QS не будет ощущаться. Однако исследований ингибиторов синтеза сигнальных молекул немного, и данные очень ограничены $(49,50)$.

Распад сигнальных молекул - более изученный процесс гашения. В нем в основном участвуют ферменты, вырабатываемые микроорганиз- 
мами или другими организмами для разрушения сигнальных молекул, воспринимающих QS, что приводит к уменьшению их концентрации ниже порогового значения, как следствие, патогенные бактерии не могут экспрессировать гены и продуцировать патогенные факторы, теряя способность заразить хозяина (51-54).

Ингибирование проведения или связывания сигнальных молекул с рецепторами также играет важную роль в снижении патогенности бактерий. Исследования показали, что многие организмы могут секретировать аналоги сигналов QS, конкурировать с рецепторами сигналов бактерий, вмешиваться в регуляцию системы контроля QS и значительно снижать патогенность бактерий $(55,56)$.

В настоящее время все QSI можно классифицировать по нескольким категориям. По химической структуре QSI подразделяются на три группы: непептидные малые молекулы, пептидные и белковые QSI. Heпептидные QSI включают аналоги АГЛ, гомологи АCP (ацил-переносящий белок), L/D-S-аденозилгомоцистеин и бутирил-S-аденозил-L-метионин, пептидные QSI, в основном гомологи AIP, а также RNAIII-ингибирующий пептид (RIP) (57-59), препятствующие синтезу сигнальных молекул QS или их связыванию с рецепторами. К белковым QSI относятся антитела и ферменты (60), в частности АГЛ-ацилаза, лактоназа, оксидоредуктаза Rhodococcus и параоксаназа млекопитающих, разрушающие сигнальные молекулы (61). Кроме того, конкурирующие организмы способны лизировать сигнальные молекулы для гашения QS (62). Например, Eshcherichia coli способна поглощать AI-2, оказывая влияние на QS у Vibrio harveyi (63).

QSI разделяют на природные и синтетические. Среди природных соединений идентифицированы пептиды антагонистов, предназначенные для подавления грамположительных бактерий, и QSI, направленные на QS грамотрицательных бактерий и AI-2-опосредованный QS (64). К ним относят полифенолы, выделенные из чая или меда, аджоен из чеснока, эвгенол из гвоздики и многие соединения, продуцируемые морскими организмами и грибами (65). Среди синтетических веществ можно выделить фторурацил (5-FU) и азитромицин $(66,67)$.

QSI, скорее всего, различаются по механизмам действия, которые не всегда известны (68). Некоторые молекулы, ингибирующие QS, например азитромицин, считаются также антибиотиками, поскольку они, начиная с определенной концентрации, могут ингибировать рост бактерий (69). Идентифицированные в настоящее время ферменты QQ в основном нацелены на АГЛ и AI-2-опосредованный QS: фосфотриэстеразоподобные лактоназы, лактоназы, ацилазы и оксидоредуктазы деградируют сигналы АГЛ, у последнего фермента мишенью также служит АI-2 (70). В связи с этим была проделана большая исследовательская работа по поиску альтернативных подходов для предотвращения QS $(71,72)$.

Скрининг природных антимикробных средств. Фермен$m ы$. В настоящее время известно более 2000 различных ферментов. Ферменты сгруппированы в шесть классов - оксидоредуктазы, трансферазы, гидролазы, лиазы (синтазы), изомеразы и лигазы (73).

Существует несколько коммерческих препаратов гидролазы, эффективных против микробной биопленки, - Spezyme GA300, Pandion, Resinase A2X и Paradigm (74). Субстратами для гидролаз служат пептидогликаны - компоненты бактериальной клеточной стенки, отвечающие за ее жесткость. Деградация клеточной стенки приводит к лизису клеток из-за нарушения внутреннего осмотического давления. Грамотрицательные бактерии менее чувствительны к бактериолитическим ферментам, чем грам- 
положительные, из-за различий в структуре клеточной стенки (73).

Протеазы - ферменты, гидролизующие белки, к ним, в частности, относятся субтилизины, широко используемые для контроля биопленок в промышленных условиях (75). Лизостафин - эндопептидаза, лизирующая клеточные стенки стафилококков, включая метициллин-резистентный Staphylococcus aureus (MRSA), посредством расщепления пентаглициновых поперечных сшивок пептидогликана (76). Введение лизостафина в комбинации с оксациллином или ванкомицином усиливало антимикробный эффект (77).

Среди ферментов, гидролизующих полисахариды, антимикробными свойствами обладают лизоцим, альгинатлиаза, дисперсин В и амилаза. Лизоцим, иммобилизованный в хитозан, был эффективен в подавлении порчи пищевых продуктов микроорганизмами (78). Альфа-амилаза гидролизует биопленки Staphylococcus aureus (79). Комбинация протеаз и амилаз эффективно удаляла биопленки Pseudomonas fluorescens (80).

Антимикробные ферменты бактерий. К ферментам, гасящим QS и способным деградировать QS-сигнальные ацилированные гомосерин-лактоновые аутоиндукторы, относятся АГЛ-лактоназы, АГЛ-ацилазы, декарбоксилазы и дезаминазы (62). Эти ферменты обнаружены у бактерий из разных филумов - Actinobacteria, Rhodococcus, Arthrobacter, Streptomyces, Firmicutes, Bacillus, Oceanobacillus, Anabaena, Cyanobacteria, Proteobacteria, Alteromonas, Comamonas, Halomonas, Hyphomonas, Pseudomonas aeruginosa, Klebsiella pneumoniae, Ralstonia и Stappia (81). У этих бактерий имеются либо АГЛ-лактоназы, либо АГЛ-ацилазы; Rhodococcus erythropolis - единственный известный организм, обладающий двумя ферментами $(82,83)$. Интеpecно, что Bacillus thuringiensis не продуцирует QS-сигнал, но продуцирует АГЛ-лактоназу (84). Микроорганизмы, секретирующие бактериолитические ферменты (например, стрептомицеты), обычно экспрессируют комплекс из нескольких ферментов с разной специфичностью для деградации клеточной стенки.

Применение липазы считается инновационным и экологически чистыми подходом для контроля биопленки из-за литической и диспергирующей активности этого фермента. Большинство липаз, используемых в промышленности, имеют микробное происхождение. Липазы катализируют гидролиз сложных эфиров длинноцепочечных алифатических кислот. Этот фермент синтезируют эукарии, грибы, актиномицеты, дрожжи, бактерии и археи. Бактериальные липазы продуцируют представители родов Bacillus, Penicillium, Staphylococcus, Pseudomonas и Aspergillus. Также исследовались свойства $\alpha$-амилазы, $\beta$-глюканазы, липазы (ЕС 3.1.1.3) и протеазы, разрушающих проточные биопленки Pseudomonas fluorescens. Четыре фермента показали умеренное снижение числа колониеобразующих единиц в биопленке $(85,86)$.

Антимикробные ферменты ж⿻ивотных. Ацилаза I свиной почки инактивировала сигналы QS и предотвращала образование биопленки у Pseudomonas putida и Aeromonas hydrophila (87). Параоксоназы млекопитающих оказывают гидролитическое действие на сложные эфиры и лактоны (88). Лактоназы млекопитающих отличается от выделенных из бактерий тем, что у млекопитающих фермент нуждается в активном ионе кальция (88). Эпителиальные клетки человека обладают способностью инактивировать аутоиндуктор АГЛ, синтезируемый Pseudomonas aeruginosa (89).

Панкреатическая липаза катализирует синтез жирных кислот у бактерий, поэтому она может служить потенциальным антибактериальным средством, эффективным против многих бактериальных штаммов (86). 
Ферменты млекопитающих параоксоназа и лактоназа относятся к QSI и могут влиять на развитие инфекций, вызванных Pseudomonas aeruginosa (61).

Антимикробные ферменты растений. Лакказы, являющиеся ферментами QSI, обнаружены в экстрактах, полученных из плодов, цветов, листьев и коры Laurus nobilis, Combretum albiflorum и Sonchus oleraceus, анализ проводили с использованием Chromobacterium violaceum (90). Аллииназа и тиолзависимый фермент, выделенные из чеснока и лекарственных растений, выступают в качестве QSI для Pseudomonas aeruginosa (91). Лактоназа, присутствующая в клевере, лотосе, бобовых, горохе, батате, люцерне, показала способность деградировать АГЛ у штаммов Chromobacterium violaceum CV12472 и CVO26 (92).

Ферменты морских организмов. Водоросли, например Laminaria digitata, обладают ферментом галопероксидазой, проявляющим способность ингибировать QS (QQ) через окисления сигнальной группы АГЛ (93). Красные водоросли Delisea pulchra содержат галогенированные фураноны, которые сходны по структуре с бактериальными АГЛ и могут блокировать рецепторы, препятствуя процессу QS $(94,95)$. Альгинатные лиазы (ферменты, обнаруженные в водорослях, беспозвоночных и морских микроорганизмах) используются в сочетании с гентамицином против Pseudomonas aeruginosa при инфекциях дыхательных путей у больных муковисцидозом $(96,97)$.

Антимикробные пищеварительные ферменты. Пищеварительные ферменты, дополняющие рацион для повышения коэффициента кормовой эффективности и стимуляции всасывания питательных веществ, также влияют на бактериальную популяцию в пищеварительном тракте (98). Некоторые ферменты, например фитазы и ферменты, расщепляющие углеводы, представлены на рынке в качестве кормовых добавок для моногастричных животных (99). Такие добавки повышают обеспеченность кишечной флоры питательными веществами, что позволяет ей лучше конкурировать с патогенными бактериями (98). У цыплят-бройлеров добавление препаратов ксиланазы и лизоцима в рацион минимизировало желудочнокишечные поражения, снижая обилие Clostridium perfringens в подвздошной кишке (100).

Информация о практическом применении кормовых добавок на основе ферментов с антимикробными свойствами ограничена. Однако очевидно, что добавки, ингибирующие QS, весьма перспективны и будут особенно востребованы в животноводстве, если принять во внимание современные объемы применения антибиотиков в этой отрасли. К сожалению, к недостаткам ферментных препаратов - ингибиторов QS относится относительная дороговизна их промышленного производства (101).

Растительные экстракты и эфирные масла (ЭМ). Растительные субстанции, известные как фитобиотики, применяются в кормлении животных в качестве антиоксидантных, антимикробных, противовоспалительных и противопаразитарных средств $(102,103)$. Многие растения обладают полезными многофункциональными свойствами, и полученные из них биоактивные вещества могут благоприятно воздействовать на организм животного. Экстракты растений обычно считаются безопасными, они эффективны против некоторых бактерий, широко используются в кормах в качестве стимуляторов роста и для защиты животных, проявляя антиоксидантное, противомикробное и иммуностимулирующее действие $(103,104)$.

В свиноводстве рекомендовано применение орегано, корицы, мексиканского перца, тимьяна для подавления патогенной микрофлоры в кишечнике (105-107), сангровит и экстракт чеснока, содержащий аллицин, 
способны увеличить прирост живой массы (108, 109), тимьян, гвоздика, эвгенол повышают продуктивность свиней $(110,111)$. Сообщается о положительном влиянии фитогенных кормовых добавок на показатели прироста живой массы птицы (112).

Фитобиотические соединения представлены фенолами/полифенолами, алкалоидами, терпеноидами/ЭМ и лектинами/полипептидами (113). Растительные экстракты оказывают антимикробное действие in vitro при МПК (минимальная подавляющая концентрация) 100-1000 мкг/мл (114). Некоторые фитобиотики против патогенных микроорганизмов проявляют свойства QSI, поскольку их химическая структура подобна структуре АГЛ (115). Кроме того, гамма-аминомасляная кислота, структурно сходная с индукторами оперона attKLM, активирует экспрессию колируемой им лактоназы AttM, которая, в свою очередь, инактивирует сигнал QS (116). Флавоноиды кемпферол, нарингенин, кверцетин и апигенин действуют как QSI, ингибируя аутоиндукторы HAI-1 или AI-2 QS-контролируемой биолюминесценции в Vibrio harveyi (117). Катехины, продуцируемые растениями чая, могут активировать АГЛ-лактоназу и подавлять перенос конъюгативной R-плазмиды Escherichia coli, приводя к ее утрате (118). Фурокумарины и розмариновая кислота, присутствующие в грейпфрутовом соке и корнях сладкого базилика, нарушают образование биопленок соответственно у Escherichia coli и Pseudomonas aeruginosa (119). Тимол в настоящее время используется в комбинации с ванкомицином и EDTA в качестве антимикробного средства (120). Кроме того, комбинированное действие антибиотика тобрамицина и некоторых растительных экстрактов (циннамальдегида и гидрата байкалина в качестве QSI) было эффективным против Burkholderia cenocepacia и Pseudomonas aeruginosa (121-123). Изучалось воздействие экстрактов лекарственных трав Artemisiae argyi, Cortex dictamni и Solanum melongena на Pseudomonas aeruginosa (124). Также было обнаружено, что флавоноиды Citrus sinensis способны ингибировать сигналы QS, что может значительно снизить концентрацию сигнальных молекул, секретируемых Yersinia enterocolitica, и нарушить образование биопленок, не влияя на рост бактерий (125).

Экстракт коры дуба обыкновенного Quercus robur широко использовали в животноводстве, в том числе для частичной замены антибиотиков. Он подавляет развитие представителей патогенной микрофлоры кишечника сельскохозяйственной птицы на мясопептонном агаре благодаря анти-QS эффектами, что может быть полезно при разработке методов контроля бактериальных инфекций (126).

Перспективными представляются исследования по оценке эффективности QSI в кормлении сельскохозяйственной птицы (127). В экстракте Quercus cortex было обнаружено семь компонентов с анти-QS активностью (в порядке убывания): пирогаллол, пропилрезорцин, кумарин, скополетин, конифериловый спирт, ванилин, антиарол (128). Экстракт проявляет наиболее выраженную и стабильную анти-QS активность при отсутствии в его составе очевидных антибактериальных веществ (129). Это позволяет использовать QSI, выделенные из коры дуба, в качестве кормовой добавки для сельскохозяйственной птицы, в том числе в сочетании с другими кормовыми добавками, среди которых можно выделить пробиотики и антибиотики в малых дозах (130). Также известно, что экстракт коры дуба в рационе коров увеличивает численность микроорганизмов, разлагающих целлюлозу и другие полисахариды, что стимулирует активность различных гидролаз в рубцовой жидкости (131).

Использование ЭМ рассматривается в качестве перспективного 
подхода при борьбе с эпидемиями, вызванными мультирезистентными бактериями. ЭМ лимона, тимьяна белого, корицы, эвкалипта и лимонника показали высокий антибактериальный эффект в отношении некоторых резистентных штаммов, в частности представителей родов Streptococcus, Candida и MRSA $(132,133)$. Сообщалось о синергическом эффекте между ЭМ и антибиотиками: масла Mentha piperita, Thymus vulgaris и Rosmarinus officinalis в сочетании с ципрофлоксацином проявляли более выраженный антимикробный эффект (134). Также анти-QS активность эфирного масла или его компонентов влияет на экспрессию AI (135).

Анализируя применение лекарственных трав и их экстрактов в животноводстве, следует отметить, что из-за сложного состава их комплексные токсикологические исследования и оценка безопасности затруднены. Необходима идентификация биологически активных компонентов добавок на основе растительного сырья и количественная оценка их влияния на эффективность конверсии корма, улучшение физиологических показателей и состояние здоровья животных. В настоящее время добавки, представленные на рынке, не соответствуют принципу отслеживаемости и эффективности. При использовании в больших количествах (1-2 \%, иногда до $5 \%$ рациона) они могут негативно повлиять на животных, в частности на процессы пищеварения и усвоение кормов. Важно также учитывать возможные эффекты фитогенных добавок при их сочетании с другими кормовыми добавками. Имеются данные о неблагоприятных последствиях совместного применения растительных препаратов с ферментными (136) и с белками, приводящего к их частичной денатурации (100). Хотя фитобиотики представляют собой группу природных субстанций, прежде чем разрешить широкое применение таких кормовых добавок в животноводстве, необходимы дополнительные исследования механизмов их действия, совместимости с рационом, токсичности и безопасности.

Комбинированное воздействие антимикробных препаратов. Сочетание нескольких препаратов может дать синергетический эффект за счет разнообразия механизмов, необходимых для преодоления рецидивирующей бактериальной коммуникации и уничтожения персистирующих клеток (73). Состав таких полипрепаратных коктейлей не ограничивается антибиотиками и может включать сочетания антибиотиков с природными соединениями, которые обладают способностью QQ и действуют, как неантибиотические адъюванты. Комбинированное применение усиливает антимикробный эффект и предотвращает развитие бактериальной резистентности (137), поскольку разрушение биопленки делает бактерии более чувствительными даже к низким дозам антибиотиков. При сочетании антибиотиков и QSI показана эффективность против резистентных штаммов при стафилококковой инфекции, когда чувствительность бактерий к коммерческим антибиотикам повышалась с помощью ингибитора QS - RNAIII-ингибирующего пептида (RIP, YSPWTNF-NH2) (138, 139). Сообщалось, что QSI, например фуранон C30, патулин, пенициловаякислота и экстракт чеснока, повышают чувствительность Pseudomonas aeruginosa к тобрамицину и фагоцитарную активность лейкоцитов $(8,71)$. Большой интерес исследователей вызывают природные антимикробные соединения, которые могут быть использованы в качестве адъювантов антибиотиков (73).

Также изучалась комбинированная терапия с QQ при инфекциях, вызванных Pseudomonas aeruginosa. Применение бензамид-бензимидазола ингибирует регулятор MvfR (PqsR) QS, приводит к снижению образования биопленки и восстанавливает восприимчивость к антибиотикам $(140,141)$. 
Гидрат байкалина и гамамелитаннин (соответственно АГЛ-ориентированный QSI и пептидный QSI) усиливают разрушение биопленки как у грамотрицательных (Pseudomonas aeruginosa и Burkholderia cepacia), так и у грамположительных (Staphylococcus aureus) бактерий и показывают синергетический эффект in vitro и in vivo при сочетании соответственно с тобрамицином и клиндамицином или ванкомицином (121). Эффективность широкого спектра антибиотиков - аминогликозидов $(142,143)$, хинолонов (144), полипептидных антибиотиков $(145,146)$, цефалоспоринов и гликопептидов $(141,147)$ - повышается за счет добавления QSI.

Полученные результаты показывают, что QSI - потенциальные инструменты повышения чувствительности микроорганизмов к антибиотикам и, следовательно, снижения активных доз последних. Кроме того, аналогичную тенденцию и эффективность отмечали для сочетания лактоназы (QQ) и антибиотика ципрофлоксацина в опытах на мышах (148). Показано, что комбинация противомикробных препаратов и QQ дает обнадеживающий результат. Следовательно, применение QQ может быть эффективной стратегией для снижения применяемых доз антибиотиков, что важно для решения проблемы растущей устойчивости к ним у сельскохозяйственных животных.

Таким образом, вещества, выступающие в качестве альтернативы антибиотикам, должны соответствовать набору критериев: быть нетоксичными, не иметь побочных эффектов, легко выводиться из организма, не стимулировать резистентность бактерий, стабильно сохраняться в кормах, не разлагаться в желудочно-кишечном тракте, не загрязнять окружающую среду, не влиять на вкусовые качества, убивать патогенную микрофлору или подавлять ее рост, не затрагивая нормофлору, а также улучшать эффективность усвоения питательных веществ корма и показатели роста животных. В настоящее время не известны альтернативные антибиотикам соединения, соответствующие перечисленным требованиям. Существующие коммерческие ферментые препараты, а также препараты ферментов, ингибирующие биопленки и подавляющие кворум, которые находятся в стадии разработки, нестабильны и легко разлагаются в пищеварительном тракте. Кроме того, прямой противомикробный эффект у антибиотиков выше, чем у альтернативных соединений. Антибиотические препараты производятся из одного и относительно чистого активного субстрата с высокой стабильностью, их качество обеспечено длительной производственной практикой. Одна из рекомендаций - использовать некоторые из природных антимикробных соединений в сочетании с более низкими дозами антибиотиков. Такое совместное применение представляется самым эффективным и быстрым способом ограничить неблагоприятные последствия от использования антибиотиков и избежать формирования бактериальной резистентности. Это позволит минимизировать экономические потери, вызванные инфекциями, и сохранить высокую активность антибиотиков против патогенов при необходимости проводить эффективную антибиотикотерапию.

ФГБНУ ФНЦ Биологических систем и агротехнологий РАН, Поступила в редакцию 460000 Россия, г. Оренбург, ул. 9 Января, 29,

e-mail: christinakondrashova94@yandex.ru $₫$, kosyan.diana@mail.ru,

28 августа 2020 года

atlander-kn@mail.ru, 1sv74@list.ru

Sel'skokhozyaistvennaya biologiya [Agricultural Biology], 2020, V. 55, № 6, pp. 1073-1089

PROSPECTS OF ANTIQUORUM SUBSTANCES AS AN ALTERNATIVE 


\title{
TO ANTIBIOTIC THERAPY IN ANIMAL HUSBANDRY
}

\author{
(review)
}

\author{
K.S. Kondrashova ${ }^{凶}$, D.B. Kosyan, K.N. Atlanderova, S.V. Lebedev
}

Federal Research Centre of Biological Systems and Agrotechnologies RAS, 29, ul. 9 Yanvarya, Orenburg, 460000, e-mail christinakondrashova94@yandex.ru (corresponding author $ه$ ), kosyan.diana@mail.ru, atlander-kn@mail.ru, 1sv74@list.ru

ORCID:

Kondrashova K.S. orcid.org/0000-0003-4907-9656

Kosyan D.B. orcid.org/0000-0002-2621-108X

Atlanderova K.N. orcid.org/0000-0003-3977-4831

The authors declare no conflict of interests

Acknowledgements:

Performed in accordance with the FRC BSAT RAS research plan for 2019-2021 within the framework of state order No. 0526-2019-0002

Received August 28, 2020

doi: 10.15389/agrobiology.2020.6.1073eng

Abstract

Frequent and inappropriate use of antibiotics in animal husbandry threatens to expand the spectrum of antibiotic-resistant bacteria. Quorum sensing (QS) is one of the mechanisms responsible for this process. For its implementation, bacteria use autoinducers, the special signaling molecules for information exchange (A.A. Miller et al., 2011). The studies to give insight of this mechanism have shed light on the existence of substances that act as Quorum sensing inhibitors (quorum suppressors) (B. Remy et al., 2018), which made such studies even more relevant (J. Bzdreng et al., 2017). In our review, we have summarized the latest data on the search and development of the biologically active compounds that can become an alternative to antibiotic drugs used in animal husbandry. These include bacterial enzymes (AGL-lactonases, AGL-acylases, decarboxylases, and deaminases) that can degrade quorum sensing signal autoinducers (V.C. Kalia et al., 2011), as well as $\alpha$-amylases, $\beta$-glucanases, lipases, and proteases involved in the destruction of biofilms ( $R$. Sharma et al., 2001). The antimicrobial properties are also characteristic of animal enzymes acylase I (D. Paul et al., 2010), paraoxonase (J.F. Teiber et al., 2008), and lactonase, plant enzymes laccase (R. Al-Hussaini et al., 2009), alliinase, thiol-dependent enzyme and lactonase derived from garlic and medicinal plants (A. Adonizio et al., 2008), enzymes of marine organisms, particularly bromoperoxidase of the algae Laminaria digitata, alginate lyases from algae, invertebrates, and marine microorganisms, and halogenated furanones of Delisea pulchra (S.A. Borchardt et al., 2001; M. Manefield et al., 2000). In addition, we can distinguish antimicrobial digestive enzymes used as feed additives, e.g., phytase (O. Adeola et al., 2011), xylanase and lysozyme (G. Cheng et al., 2014). Studies of phytobiotics and essential oils as quorum sensing inhibitors are promising (V.I. Fisinin et al., 2018). Their inhibitory ability is shown due to the similarity of the chemical structures of some plant extracts to the structure of acyl-homoserine-lactone and inactivation of signaling molecules (R. Chevrot et al., 2006; F. Nazzaro et al., 2013). Another prospective alternative is the use of antimicrobial combinatins enabling a synergistic effect due to the variety of mechanisms of overcoming the recurrent bacterial communications and destroying persistent bacterial cells. These polypeptide cocktails may include the combination of antibiotics with natural compounds. The amtimicrobial efficacy has shown for combination of tobramycin and some plant extracts, partilularly cinnamaldehyde and baykalin hydrate against Burkholderia cenocepacia and Pseudomonas aeruginos (G. Brackman et al., 2011), a wide range of antibiotics, e.g., aminoglycosides (T.H. Jakobsen et al., 2012; M. Stenvang et al., 2016), quinolones (Q. Guo et al., 2016), polypeptide antibiotics (A. Furiga et al., 2016; Z.P. Bulman et al., 2017), cephalosporins and glycopeptides (D. Maura et al., 2017), and various quorum sensing inhibitors.

Keywords: quorum sensing, antibiotics, resistance, bacteria, plant extracts, enzymes.

\section{R E F E R E N C ES}

1. Kalia V.C., Rani A., Lal S., Cheema S., Raut C.P. Combing databases reveals potential antibiotic producers. Expert Opinion on Drug Discovery, 2007, 2(2): 211-224 (doi: 10.1517/17460441.2.2.211).

2. Stanton T.B. A call for antibiotic alternatives research. Trends in Microbiology, 2013, 21(3): 111-113 (doi: 10.1016/j.tim.2012.11.002).

3. Marshall B.M., Levy S.B. Food animals and antimicrobials: impacts on human health. Clinical Microbiology Reviews, 2011, 24(4): 718-733 (doi: 10.1128/CMR.00002-11).

4. Vinogradova K.A., Bulgakova V.G., Polin A.N., Kozhevin P.A. Antibiotiki i khimioterapiya, 2013, 58(5-6): 38-48 (in Russ.).

5. Castanon J.I. History of the use of antibiotic as growth promoters in European poultry feeds. Poultry Science Journal, 2007, 86(11): 2466-2471 (doi: 10.3382/ps.2007-00249).

6. Borchardt R.A., Rolston K.V. Antibiotic shortages: effective alternatives in the face of a grow- 
ing problem. JAAPA: official journal of the American Academy of Physician Assistants, 2013, 26(2): 13-18 (doi: 10.1097/01720610-201302000-00004).

7. Cooper M.A., Shlaes D. Fix the antibiotics pipeline. Nature, 2011, 472: 32-32 (doi: 10.1038/472032a).

8. Rasmussen T.B., Skindersoe M.E., Bjarnsholt T., Phipps R.K., Christensen K.B., Jensen P.O. Identity and effects of quorum sensing inhibitors produced by Penicillium species. Microbiology, 2005, 151(5): 1325-1340 (doi: 10.1099/mic.0.27715-0).

9. CHerkashina N.V., Drozdova L.I., Makhortov V.L., Vasil'ev P.G., Shcherbakov M.G., Demina L.V., Il'yazov A.A., Sirik M. Agrarnyi vestnik Urala, 2011, 82(3): 39-42 (in Russ.).

10. Vranakis I., Goniotakis I., Psaroulaki A., Sandalakis V., Tselentis Y., Gevaert K. Proteome studies of bacterial antibiotic resistance mechanisms. Journal of Proteomics, 2014, 97: 88-99 (doi: 10.1016/j.jprot.2013.10.027).

11. Kester J.C., Fortune S.M. Persisters and beyond: mechanisms of phenotypic drug resistance and drug tolerance in bacteria. Critical Reviews in Biochemistry and Molecular Biology, 2014, 49(2): 91-101 (doi: 10.3109/10409238.2013.869543).

12. Woo P.C., To A.P., Lau S.K., Yuen K.Y. Facilitation of horizontal transfer of antimicrobial resistance by transformation of antibiotic-induced cell-wall-deficient bacteria. Medical $\mathrm{Hy}$ potheses, 2003, 61(4): 503-508 (doi: 10.1016/S0306-9877(03)00205-6).

13. Norman A., Hansen L.H., Sørensen S.J. Conjugative plasmids: vessels of the communal gene pool. Philosophical Transactions of the Royal Society B: Biological Sciences, 2009, 364(1527): 2275-2289 (doi: 10.1098/rstb.2009.0037).

14. Martinez J.L., Baquero F. Mutation frequencies and antibiotic resistance. Antimicrobial Agents and Chemotherapy, 2000, 44(7): 1771-1777 (doi: 10.1128/AAC.44.7.1771-1777.2000).

15. Cirz R.T., Chin J.K., Andes D.R., de Crécy-Lagard V., Craig W.A., Romesberg F.E. Inhibition of mutation and combating the evolution of antibiotic resistance. PLoS Biology, 2005, 3(6): e176 (doi: 10.1371/journal.pbio.0030176).

16. Kohanski M.A., DePristo M.A., Collins J.J. Sublethal antibiotic treatment leads to multidrug resistance via radical-induced mutagenesis. Molecular Cell, 2010, 37(3): 311-320 (doi: 10.1016/j.molcel.2010.01.003).

17. Sánchez-Romero M.A., Casadesús J. Contribution of phenotypic heterogeneity to adaptive antibiotic resistance. Proceedings of the National Academy of Sciences, 2014, 111(1): 355-360 (doi: 10.1073/pnas.1316084111).

18. Wright G.D. Bacterial resistance to antibiotics: enzymatic degradation and modification. $A d-$ vanced Drug Delivery Reviews, 2005, 57(10): 1451-1470 (doi: 10.1016/j.addr.2005.04.002).

19. Ramirez M.S., Tolmasky M.E. Aminoglycoside modifying enzymes. Drug Resistance Updates, 2010, 13(6): 151-171 (doi: 10.1016/j.drup.2010.08.003).

20. Tillotson G.S., Theriault N. New and alternative approaches to tackling antibiotic resistance. F1000Prime Reports, 2013, 5: 51 (doi: 10.12703/P5-51).

21. Wilson D.N. Ribosome-targeting antibiotics and mechanisms of bacterial resistance. Nature Reviews Microbiology, 2014, 12(1): 35-48 (doi: 10.1038/nrmicro3155).

22. Liu L.Y., Ye C.X., Soteyome T., Zhao X.H., Xia J., Xu W.Y., Mao Y.Z., Peng R.X., Chen J.X., Xu Z.B. Inhibitory effects of two types of food additives on biofilm formation by foodborne pathogens. Microbiology Open, 2019, 8(9): e00853 (doi: 10.1002/mbo3.853).

23. Li X.Z., Nikaido H. Efflux-mediated drug resistance in bacteria. Drugs, 2013, 69(12): 15551623 (doi: 10.2165/11317030-000000000-00000).

24. Poole K., Russell A., Lambert P. Mechanisms of antimicrobial resistance: opportunities for new targeted therapies. Advanced Drug Delivery Reviews, 2005, 57(10): 1443-1445 (doi: 10.1016/j.addr.2005.05.001).

25. Alekshun M.N., Levy S.B. Molecular mechanisms of antibacterial multidrug resistance. Cell, 2007, 128(6): 1037-1050 (doi: 10.1016/j.cell.2007.03.004).

26. Kumar S., Varela M.F. Biochemistry of bacterial multidrug efflux pumps. International Journal of Molecular Science, 2012, 13(4): 4484-4495 (doi: 10.3390/ijms13044484).

27. Wasaznik A., Grinholc M., Bielawski K.P. Active efflux as the multidrug resistance mechanism. Postepy higienyi medycyny doswiadczalnej (Online), 2009, 63: 123-133.

28. Boucher H.W., Talbot G.H., Bradley J.S., Edwards J.E., Gilbert D., Rice L.B. Bad bugs, no drugs: No ESKAPE! An update from the Infectious Diseases Society of America. Clinical Infectious Diseases, 2009, 48(1): 1-2 (doi: 10.1086/595011).

29. Miller A.A., Miller P.F. Emerging trends in antibacterial discovery: answering the call to arms. Caister Academic Press, Norfolk, UK, 2011.

30. Anwar H., Dasgupta M.K., Costerton J.W. Testing the susceptibility of bacteria in biofilms to antibacterial agents. Antimicrobial Agents and Chemotherapy, 1990, 34(11): 2043-2046 (doi: 10.1128/aac.34.11.2043).

31. Huma N., Shankar P., Kushwah J., Bhushan A., Joshi J., Mukherjee T. Diversity and polymorphism in AHL-lactonase gene (aiiA) of Bacillus. Journal of Microbiology and Biotechnology, 2011, 21(10): 1001-1011 (doi: 10.4014/jmb.1105.05056). 
32. Jamuna Bai A., Rai V.R. Bacterial quorum sensing and food industry. Comprehensive Reviews in Food Science and Food Safety, 2011, 10(3): 183-1193 (doi: 10.1111/J.1541-4337.2011.00150.X).

33. Remy B., Mion S., Plener L., Elias M., Chabriure E., Daudé D. Interference in bacterial quorum sensing: a biopharmaceutical perspective. Frontiers in Pharmacology, 2018, 9: 203 (doi: 10.3389/fphar.2018.00203).

34. Bzdreng J., Daude D., Remy B., Jacquet P., Plener L., Elias M. Biotechnological applications of quorum quenching enzymes. Chemico-Biological Interactions, 2017, 267: 104-115 (doi: 10.1016/j.cbi.2016.05.028).

35. Khmel' I.A. Mikrobiologiya, 2006, 75(4): 457-464 (in Russ.).

36. Heilmann S., Krishna S., Kerr B. Why do bacteria regulate public goods by quorum sensing? - how the shapes of cost and benefit functions determine the form of optimal regulation. Frontiers in Microbiology, 2015, 6: 767 (doi: 10.3389/fmicb.2015.00767).

37. Monnet V., Juillard V., Gardan R. Peptide conversations in Gram-positive bacteria. Critical Reviews in Microbiology, 2016, 42(3): 339-351 (doi: 10.3109/1040841X.2014.948804).

38. Schuster M., Sexton D.J., Diggle S.P., Greenberg E.P. Acyl-homoserine lactone quorum sensing: from evolution to application. Annual Review of Microbiology, 2013, 67: 43-63 (doi: 10.1146/annurev-micro-092412-155635).

39. Lee J., Zhang L. The hierarchy quorum sensing network in Pseudomonas aeruginosa. Protein Cell, 2015, 6(1): 26-41 (doi: 10.1007/s13238-014-0100-x).

40. Plener L., Lorenz N., Reiger M., Ramalho T., Gerland U., Jung K. The phosphorylation flow of the Vibrio harveyi quorum-sensing cascade determines levels of phenotypic heterogeneity in the population. Journal of Bacteriology, 2015, 197(10): 1747-1756 (doi: 10.1128/JB.02544-14).

41. Hawver L.A., Jung S.A., Ng W.L. Specificity and complexity in bacterial quorum-sensing systems. FEMS Microbiology Reviews, 2016, 40(5): 738-752 (doi: 10.1093/femsre/fuw014).

42. Zhou L., Zhang L.H., Cámara M., He Y.W. The DSF family of quorum sensing signals: diversity, biosynthesis, and turnover. Trends in Microbiology, 2017, 25(4): 293-303 (doi: 10.1016/j.tim.2016.11.013).

43. Tiaden A., Hilbi H. $\alpha$-Hydroxyketone synthesis and sensing by Legionella and Vibrio. Sensors, 2012, 12(3): 2899-2919 (doi: 10.3390/s120302899).

44. Kendall M.M., Sperandio V. Quorum sensing by enteric pathogens. Current Opinion in Gastroenterology, 2007, 23(1): 10-15 (doi: 10.1097/MOG.0b013e3280118289).

45. Heeb S., Fletcher M.P., Chhabra S.R., Diggle S.P., Williams P., Camara M. Quinolones: from antibiotics to autoinducers. FEMS Microbiology Reviews, 2011, 35(2): 247-274 (doi: 10.1111/j.1574-6976.2010.00247.x).

46. Chen X., Schauder S., Potier N., Van Dorsselaer A., Pelczer I., Bassler B. L. Structural identification of a bacterial quorum-sensing signal containing boron. Nature, 2002, 415: 545-549 (doi: 10.1038/415545a).

47. Dong Y.H., Xu J. L., Li X.Z., Zhang, L. H. AiiA, an enzyme that inactivates the acylhomoserine lactone quorum-sensing signal and attenuates the virulence of Erwinia carotovora. Proceedings of the National Academy of Sciences, 2000, 97(7): 3526-3531 (doi: 10.1073/pnas.97.7.3526).

48. Pumbwe L., Skilbeck C.A., Wexler H.M. Presence of quorum-sensing systems associated with multidrug resistance and biofilm formation in Bacteroides fragilis. Microbial Ecology, 2008, 56(3): 412-419 (doi: 10.1007/s00248-007-9358-3).

49. Zhao X., Yu Z., Ding T. Quorum-sensing regulation of antimicrobial resistance in bacteria. Microorganisms, 2020, 8(3): 425 (doi: 10.3390/microorganisms8030425).

50. Tang K., Zhang X.-H. Quorum quenching agents: resources for antivirulence therapy. Marine Drugs, 2014, 12(6): 3245-3282 (doi: 10.3390/md12063245).

51. Park J., Jagasia R., Kaufmann G.F., Mathison J.C., Ruiz D.I., Moss J.A. Infection control by antibody disruption of bacterial quorum sensing signaling. Chemistry \& Biology, 2007, 14(10): 1119-1127 (doi: 10.1016/j.chembiol.2007.08.013).

52. Kato N., Morohoshi T., Nozawa T., Matsumoto H., Ikeda T. Control of gram-negative bacterial quorum sensing with cyclodextrin immobilized cellulose ether gel. Journal of Inclusion Phenomena and Macrocyclic Chemistry, 2006, 56: 55-59 (doi: 10.1007/s10847-006-9060-y).

53. Kato N., Tanaka T., Nakagawa S., Morohoshi T., Hiratani K., Ikeda T. Control of virulence factor expression in opportunistic pathogens using cyclodextrin immobilized gel. Journal of Inclusion Phenomena and Macrocyclic Chemistry, 2007, 57: 419-423 (doi: 10.1007/s10847-006-9228-5).

54. Morohoshi T., Tokita K., Ito S., Saito Y., Maeda S., Kato N. Inhibition of quorum sensing in gram-negative bacteria by alkylamine-modified cyclodextrins. Journal of Bioscience and Bioengineering, 2013, 116(2): 175-179 (doi: 10.1016/j.jbiosc.2013.01.022).

55. Fetzner S. Quorum quenching enzymes. Journal of Biotechnology, 2015, 201: 2-14 (doi: 10.1016/j.jbiotec.2014.09.001).

56. Carlier A., Chevrot R., Dessaux Y., Faure D. The assimilation of gamma-butyrolactone in Agrobacterium tumefaciens C58 interferes with the accumulation of the N-acyl-homoserine lactone signal. Molecular Plant-Microbe Interactions, 2004, 17(9): 951-957 (doi: 10.1094/MPMI.2004.17.9.951). 
57. Parsek M.R., Val D.L., Hanzelka B.L., Cronan J.E. Jr., Greenberg E.P. Acyl homoserinelactone quorum-sensing signal generation. Proceedings of the National Academy of Sciences, 1999, 96(8): 4360-4365 (doi: 10.1073/pnas.96.8.4360).

58. Hentzer M., Wu H., Andersen J.B., Riedel K., Rasmussen T.B., Bagge N. Attenuation of Pseudomonas aeruginosa virulence by quorum sensing inhibitors. EMBO Journal, 2013, 22(15): 3803-3815 (doi: 10.1093/emboj/cdg366).

59. Dell'Acqua G., Giacometti A., Cironi O., Ghiselli R., Saba V., Scalise G. Suppression of drug-resistant Staphylococcal infections by the quorum-sensing inhibitor RNAIII-inhibiting peptide. Journal of Infectious Diseases, 2004, 190(2): 316-320 (doi: 10.1086/386546).

60. Amara N., Krom B.P., Kaufmann G.F., Meijler M.M. Macromolecular inhibition of quorum sensing: enzymes, antibodies, and beyond. Chemical Reviews, 2011, 111(1): 195-208 (doi: 10.1021/cr100101c).

61. Ozer E.A., Pezzulo A., Shih D.M., Chun C., Furlong C., Lusi, A.J. Human and murine paraoxonase 1 are host modulators of Pseudomonas aeruginosa quorum-sensing. FEMS Microbiology Lettters, 2005, 253(1): 29-37 (doi: 10.1016/j.femsle.2005.09.023).

62. Kalia V.C., Purohit H.J. Quenching the quorum sensing system: potential antibacterial drug targets. Critical Reviews in Microbiology, 2011, 37(2): 121-140 (doi: 10.3109/1040841X.2010.5324790).

63. Xavier K.B., Bassler B.L. Interference with AI-2-mediated bacterial cell-cell communication. Nature, 2005, 437: 750-753 (doi: 10.1038/nature03960).

64. Singh R.P., Desouky S.E., Nakayama J. Quorum quenching strategy targeting gram-positive pathogenic bacteria. Advances in Experimental Medicine and Biology, 2016, 901: 109-130 (doi: 10.1007/5584_2016_1).

65. Delago A., Mandabi A., Meijler M. M. Natural quorum sensing inhibitors - small molecules, big messages. Israel Journal of Chemistry, 2016, 56(5): 310-320 (doi: 10.1002/ijch.201500052).

66. Ueda A., Attila C., Whiteley M., Wood T.K. Uracil influences quorum sensing and biofilm formation in Pseudomonas aeruginosa and fluorouracil is an antagonist. Microbial Biotechnology, 2009, 2(1): 62-74 (doi: 10.1111/j.1751-7915.2008.00060.x).

67. Swatton J.E., Davenport P.W., Maunders E.A., Griffin J.L., Lilley K.S., Welch M. Impact of azithromycin on the quorum sensing-controlled proteome of Pseudomonas aeruginosa. PLoS ONE, 2016, 11(1): e0147698 (doi: 10.1371/journal.pone.0147698).

68. Defoirdt T., Brackman G., Coenye T. Quorum sensing inhibitors: how strong is the evidence? Trends in Microbiology, 2013, 21(12): 619-624 (doi: 10.1016/j.tim.2013.09.006).

69. Nalca Y., Jänsch L., Bredenbruch F., Geffers R., Buer J., Häussler S. Quorum-sensing antagonistic activities of azithromycin in Pseudomonas aeruginosa PAO1: a global approach. Antimicrobial Agents and Chemotherapy, 2006, 50(5): 1680-1688 (doi: 10.1128/AAC.50.5.16801688.2006).

70. Weiland-Bräuer N., Kisch M.J., Pinnow N., Liese A., Schmitz R.A. Highly effective inhibition of biofilm formation by the first metagenome-derived AI-2 quenching enzyme. Frontiers in $\mathrm{Mi}$ crobiology, 2016, 7: 1098 (doi: 10.3389/fmicb.2016.01098).

71. Bjarnsholt T., Jensen P.Ø., Burmølle M., Hentzer M., Haagensen J.A., Hougen H.P. Pseudomonas aeruginosa tolerance to tobramycin, hydrogen peroxide and polymorphonuclear leukocytes is quorumsensing dependent. Microbiology, 2005, 151(2): 373-383 (doi: 10.1099/mic.0.27463-0).

72. Seal B.S., Lillehoj H.S., Donovan D.M., Gay C.G. Alternatives to antibiotics: a symposium on the challenges and solutions for animal production. Animal Health Research Reviews, 2013, 14(1): 78-87 (doi: 10.1017/S1466252313000030).

73. Hanafi E.M., Danial E.N. Natural antimicrobials in the pipeline and possible synergism with antibiotics to overcome microbial resistance. Asian Journal of Pharmaceutical and Clinical Research, 2019, 12(4): 15-21 (doi: 10.22159/ajpcr.2019.v12i4.30926).

74. Augustin M., Ali-Vehmas T., Atroshi F. Assessment of enzymatic cleaning agents and disinfectants against bacterial biofilms. Journal of Pharmacy and Pharmaceutical Sciences, 2004, 7(1): $55-64$.

75. Longhi C., Scoarughi G.L., Poggiali F., Cellini A., Carpentieri A., Seganti L. Protease treatment affects both invasion ability and biofilm formation in Listeria monocytogenes. Microbial Pathogenesis, 2008, 45(1): 45-52 (doi: 10.1016/j.micpath.2008.01.007).

76. Miao J., Pangule R.C., Paskaleva E.E., Hwang E.E., Kane R.S., Linhardt R.J. Lysostaphinfunctionalized cellulose fibers with antistaphylococcal activity for wound healing applications. Biomaterials, 2011, 32(36): 9557-9567 (doi: 10.1016/j.biomaterials.2011.08.080).

77. Kiri N., Archer G., Climo M.W. Combinations of lysostaphin with betalactams are synergistic against oxacillin-resistant Staphylococcus epidermidis. Antimicrobial Agents and Chemotherapy, 2002, 46(6): 2017-2020 (doi: 10.1128/aac.46.6.2017-2020.2002).

78. Lian Z., Ma Z., Wei J., Liu H. Preparation and characterization of immobilized lysozyme and evaluation of its application in edible coatings. Process Biochemistry, 2012, 47(2): 201-208 (doi: 10.1016/J.PROCBIO.2011.10.031).

79. Abaturov A.E. Polisakharidrazrushayushchie fermenty kak agenty, dispergiruyushchie bakterial'nye bioplenki. Zdorov'e rebenka, 2020, 15(4): 271-278 (doi: 10.22141/2224- 
0551.15.4.2020.208478).

80. Molobela I.P., Cloete T.E., Mervyn B. Protease and amylase enzymes for biofilm removal and degradation of extracellular polymeric substances (EPS) produced by Pseudomonas fluorescens bacteria. African Journal of Microbiology Research, 2010, 4(14): 1515-1524.

81. Romero M., Martin-Cuadrado A.B., Roca-Rivada A., Cabello A.M., Otero A. Quorum quenching in cultivable bacteria from dense marine coastal microbial communities. FEMS Microbiology Ecology, 2011, 75(2): 205-217 (doi: 10.1111/j.1574-6941.2010.01011.x).

82. Park S.Y., Hwang B.J., Shin M.H., Kim J.A., Kim H.K., Lee J.K. N-acyl-homoserine lactonase producing Rhodococcus spp. with different AHL-degrading activities. FEMS Microbiology Letters, 2006, 261(1): 102-108 (doi: 10.1111/j.1574-6968.2006.00336.x).

83. Uroz S., Oger P.M., Chapelle E., Adeline M.T., Faure D., Dessaux Y.A. Rhodococcus qsdAencoded enzyme defines a novel class of large spectrum quorum-quenching lactonases. Applied and Environmental Microbiology, 2008, 74(5): 1357-1366 (doi: 10.1128/AEM.02014-07).

84. Bentley S.D., Chater K.F., Cerdeco-Tárraga A.M., Challis G.L., Thomson N.R., James K.D. Complete genome sequence of the model actinomycete Streptomyces coelicolor A3(2). Nature, 2002, 417: 141-147 (doi: 10.1038/417141a).

85. Kumar S., Kikon K., Upadhyay A., Kanwar S.S., Gupta R. Production, purification, and characterization of lipase from thermophilic and alkaliphilic Bacillus coagulans BTS-3. Protein Expression and Purification, 2005, 41(1): 34-44 (doi: 10.1016/j.pep.2004.12.010).

86. Sharma R., Chisti Y., Banerjee U.C. Production, purification, characterization, and applications of lipases. Biotechnology Advances, 2001, 19(8): 627-662 (doi: 10.1016/s07349750(01)00086-6).

87. Paul D., Kim Y.S., Ponnusamy K., Kweon J.H. Application of quorum quenching to inhibit biofilm formation. Environmental Engineering Science, 2009, 26(8): 1319-1324 (doi: 10.1089/ees.2008.0392).

88. Teiber J.F., Horke S., Haines D.C., Chowdhary P.K., Xiao J., Kramer G.L. Dominant role of paraoxonases in inactivation of the Pseudomonas aeruginosa quorum-sensing signal N-(3oxododecanoyl)-L-homoserine lactone. Infection and Immunity, 2008, 76(6): 2512-2519 (doi: 10.1128/IAI.01606-07).

89. Stoltz D.A., Ozer E.A., Ng C.J., Yu J.M., Reddy S.T., Lusis A.J. Paraoxonase-2 deficiency enhances Pseudomonas aeruginosa quorum sensing in murine trachea epithelia. American Journal of Physiology-Lung Cellular and Molecular Physiology, 2007, 292(4): 852-860 (doi: 10.1152/ajplung.00370.2006).

90. Al-Hussaini R., Mahasneh A.M. Microbial growth and quorum sensing antagonist activities of herbal plants extracts. Molecule, 2009, 14(9): 3425-3435 (doi: 10.3390/molecules14093425).

91. Adonizio A., Kong K.F., Mathee K. Inhibition of quorum sensingcontrolled virulence factor production in Pseudomonas aeruginosa by South Florida plant extracts. Antimicrobial Agents and Chemotherapy, 2008, 52(1): 198-203 (doi: 10.1128/AAC.00612-07).

92. Fatima Q., Zahin M., Khan M.S., Ahmad I. Modulation of quorum sensing controlled behaviour of bacteria by growing seedling, seed and seedling extracts of leguminous plants. Indian Journal of Medical Microbiology, 2010, 50: 238-242 (doi: 10.1007/s12088-010-0025-kh).

93. Borchardt S.A., Allain E.J., Michels J.J., Stearns G.W., Kelly R.F., McCoy W.F. Reaction of acylated homoserine lactone bacterial signaling molecules with oxidized halogen antimicrobials. Applied and Environmental Microbiology, 2001, 67(7): 3174-3179 (doi: 10.1128/AEM.67.7.31743179.2001).

94. Manefield M., Harris L., Rice S.A., de Nys R., Kjelleberg S. Inhibition of luminescence and virulence in the black tiger prawn (Penaeus monodon) pathogen Vibrio harveyi by intercellular signal antagonists. Applied and Environmental Microbiology, 2000, 66(5): 2079-2084 (doi: 10.1128/aem.66.5.2079-2084.2000).

95. Ren D., Bedzyk L.A., Ye R.W., Thomas S.M., Wood T.K. Differential gene expression shows natural brominated furanones interfere with the autoinducer-2 bacterial signaling system of Escherichia coli. Biotechnology and Bioengineering, 2004, 88(5): 630-642 (doi: 10.1002/bit.20259).

96. Alkawash M.A., Soothill J.S., Schiller N.L. Alginate lyase enhances antibiotic killing of mucoid Pseudomonas aeruginosa in biofilms. APMIS, 2006, 114(2): 131-138 (doi: 10.1111/j.16000463.2006.apm_356.x).

97. Lamppa J.W., Ackerman M.E., Lai J.I., Scanlon T.C., Griswold K.E. Genetically engineered alginate lyase-PEG conjugates exhibit enhanced catalytic function and reduced immunoreactivity. PLoS ONE, 2011, 6(2): e17042 (doi: 10.1371/journal.pone.0017042).

98. Bedford M.R., Cowieson A.J. Exogenous enzymes and their effects on intestinal microbiology. Animal Feed Science and Technology, 2012, 173(1-2): 76-85 (doi: 10.1016/j.anifeedsci.2011.12.018).

99. Adeola O., Cowieson A.J. Board invited review: opportunities and challenges in using exogenous enzymes to improve no ruminant animal production. Journal of Animal Science, 2011, 89(10): 3189-3218 (doi: 10.2527/jas.2010-3715).

100. Cheng G., Hao H., Xie S., Wang X., Dai M, Huang L. Antibiotic alternatives: the substi- 
tution of antibiotics in animal husbandry? Frontiers in Microbiology, 2014, 5: 217 (doi: 10.3389/fmicb.2014.00217).

101. Thallinger B., Prasetyo E.N., Nyanhongo G.S., Guebitz G.M. Antimicrobial enzymes: An emerging strategy to fight microbes and microbial biofilms. Biotechnology Journal, 2013, 8(1): 97-109 (doi: 10.1002/biot.201200313).

102. Vondruskova H., Slamova R., Trckova M., Zraly Z., Pavlik I. Alternatives to antibiotic growth promoters in prevention of diarrhoea in weaned piglets: a review. Veterinary Medicine, 2010, 55(5): 199-224 (doi: 10.17221/2998-VETMED).

103. Hashemi S.R., Davoodi H. Herbal plants and their derivatives as growth and health promoters in animal nutrition. Veterinary Research Communications, 2011, 35(3): 169-180 (doi: 10.1007/s11259-010-9458-2).

104. Abreu A.C., McBain A.J., Simoes M. Plants as sources of new antimicrobials and resistancemodifying agents. Natural Product Reports, 2012, 29(9): 1007-1021 (doi: 10.1039/c2np20035j).

105. Zanchi R., Canzi E., Molteni L., Scozzoli M. Effect of Camellia sinensis L. whole plant extract on piglet intestinal ecosystem. Annals of Microbiology, 2008, 58: 147-152 (doi: 10.1007/BF03179459).

106. Manzanilla E.G., Perez J.F., Martin M., Kamel C., Baucells F., Gasa J. Effect of plant extracts and formic acid on the intestinal equilibrium of early-weaned pigs. Journal of Animal Science, 2004, 82(11): 3210-3218 (doi: 10.2527/2004.82113210X).

107. Namkung H., Li M., Gong J., Yu H., Cottrill M., De Lange C.F.M. Impact of feeding blends of organic acids and herbal extracts on growth performance, gut microbiota and digestive function in newly weaned pigs. Canadian Journal of Animal Science, 2004, 84(4): 697-704 (doi: 10.4141/A04005).

108. Borovan L. Plant alkaloids enhance performance of animals and improve the utilizability of amino acids. Krmivarstvi, 2004, 6: 36-37 (in Czech).

109. Tatara M.R., Sliwa E., Dudek K., Gawron A., Piersiak T., Dobrowolski P. Aged garlic extract and allicin improve performance and gastrointestinal tract development of piglets reared in artificial sow. Annals of Agricultural and Environmental Medicine, 2008, 15(1): 63-69.

110. Oetting L.L., Utiyama C.E., Giani P.A., Ruiz U.D., Miyada V.S. Effects of herbal extracts and antimicrobials on apparent digestibility, performance, organs morphometry and intestinal histology of weanling pigs. Brazilian Journal of Animal Science, 2006, 35(4): 1389-1397 (doi: 10.1590/S1516-35982006000500019).

111. Costa L.B., PanhozaTse M.L., Miyada V.S. Herbal extracts as alternatives to antimicrobial growth for weanling pigs. Brazilian Journal of Animal Science, 2007, 36(3): 589-595 (doi: 10.1590/S1516-35982007000300011).

112. Hashemi S.R., Davoodi H. Phytogenics as new class of feed additive in poultry industry. Journal of Animal and Veterinary Advances, 2010, 9(17): 2295-2304 (doi: 10.3923/javaa.2010.2295.2304).

113. Windisch W., Schedle K., Plitzner C., Kroismayr A. Use of phytogenic products as feed additives for swine and poultry. Journal of Animal Science, 2008, 86: E140-E148 (doi: 10.2527/jas.2007-0459).

114. Simxes M., Bennett R.N., Rosa E.A. Understanding antimicrobial activities of phytochemicals against multidrug resistant bacteria and biofilms. Natural Product Reports, 2009, 26(6): 746-757 (doi: 10.1039/b821648g).

115. Vikram A., Jayaprakasha G.K., Jesudhasan P.R., Pillai S.D., Patil B.S. Suppression of bacterial cell-cell signaling, biofilm formation and type III secretion system by citrus flavonoids. Journal of Applied Microbiology, 2010, 109(2): 515-527 (doi: 10.1111/j.1365-2672.2010.04677.x).

116. Chevrot R., Rosen R., Haudecoeur E., Cirou A., Shelp B.J., Ron E. GABA controls the level of quorum-sensing signal in Agrobacterium tumefaciens. Proceedings of the National Academy of Sciences, 2006, 103(19): 7460-1464 (doi: 10.1073/PNAS.0600313103).

117. Nazzaro F., Fratianni F., Coppola R. Quorum sensing and phytochemicals. International Journal of Molecular Sciences, 2013, 14(6): 12607-12619 (doi: 10.3390/ijms140612607).

118. Zhao W.H., Hu Z.Q., Hara Y., Shimamura T. Inhibition by epigallocatechin gallate (EGCg) of conjugative $\mathrm{R}$ plasmid transfer in Escherichia coli. Journal of Infection and Chemotherapy, 2001, 7(3): 195-197 (doi: 10.1007/s101560100035).

119. Girennavar B., Cepeda M.L., Soni K.A., Vikram A., Jesudhasan P., Jayaprakasha G.K. Grapefruit juice and its furocoumarins inhibits autoinducer signaling and biofilm formation in bacteria. International Journal of Food Microbiology, 2008, 125(2): 204-208 (doi: 10.1016/j.ijfoodmicro.2008.03.028).

120. Hamoud R., Zimmermann S., Reichling J., Wink M. Synergistic interactions in two-drug and three-drug combinations (thymol, EDTA and vancomycin) against multi drug resistant bacteria including E. coli. Phytomedicine, 2014, 21(4): 443-447 (doi: 10.1016/j.phymed.2013.10.016).

121. Brackman G., Cos P., Maes L., Nelis H.J., Coenye T. Quorum sensing inhibitors increase the susceptibility of bacterial biofilms to antibiotics in vitro and in vivo. Antimicrobial Agents and Chemotherapy, 2011, 55(6): 2655-2661 (doi: 10.1128/AAC.00045-11). 
122. Brackman G., Hillaert U., Van Calenbergh S., Nelis H.J., Coenye T. Use of quorum sensing inhibitors to interfere with biofilm formation and development in Burkholderia multivorans and Burkholderia cenocepacia. Research in Microbiology, 2009, 160(2): 144-151 (doi: 10.1016/j.resmic.2008.12.003).

123. Yang L., Rybtke M.T., Jakobsen T.H., Hentzer M., Bjarnsholt T., Givskov M. Computeraided identification of recognized drugs as Pseudomonas aeruginosa quorum-sensing inhibitors. Antimicrobial Agents and Chemotherapy, 2009, 53(6): 2432-2443 (doi: 10.1128/AAC.01283-08).

124. Wei Q., Bhasme P., Wang Z., Wang L., Wang S., Zeng Y., Wang Y., Ma L. Z., Li Y. Chinese medicinal herb extract inhibits PQS-mediated quorum sensing system in Pseudomonas aeruginosa. Journal of Ethnopharmacology, 2020, 248: 112-272 (doi: 10.1016/j.jep.2019.112272).

125. Truchado P., Gimenez-Bastida J.A., Larrosa M., Castro-Ibanez I., Espin J.C., TomasBarberan F.A., Garcia-Conesa M.T., Allende A. Inhibition of quorum sensing (QS) in Yersinia enterocolitica by an orange extract rich in glycosylated flavanones. Journal of Agricultural and Food Chemistru, 2012, 60(36): 8885-8894 (doi: 10.1021/jf301365a).

126. Maznev H.I. Entsiklopediya lekarstvennykh rastenii [Encyclopedia of medicinal plants]. M., 2004 (in Russ.).

127. Fisinin V.I., Ushakov A.S., Duskaev G.K., Kazachkova N.M., Nurzhanov B.S., Rakhmatullin Sh.G., Levakhin G.I. Mixtures of biologically active substances of oak bark extracts change immunological and productive indicators of broilers. Agricultural Biology [Sel'skokhozyaistvennaya biologiya], 2018, 53(2): 385-392 (doi: 10.15389/agrobiology.2018.2.385eng).

128. Tolmacheva A.A. Lekarstvennye rasteniya i ikh komponenty kak ingibitory sistemy quorum sensing pervogo tipa u bakterii (na primere Chromobacterium violaceum). Avtoreferat kandidatskoi dissertatsii [Medicinal plants and their components as inhibitors of the quorum sensing system of the first type in bacteria (on the example of Chromobacterium violaceum). PhD Thesis]. Saratov, 2016 (in Russ.).

129. Deryabin D.G., Tolmacheva A.A. Antibacterial and anti-quorum sensing molecular composition derived from quercus cortex (Oak bark) extract. Molecules, 2015, 20(9): 17093-17108 (doi: 10.3390/molecules200917093).

130. Duskaev G.K., Drozdova E.A., Aleshina E.S., Bezryadina A.S. Vestnik Orenburgskogo gosudarstvennogo universiteta, 2017, 211(11): 84-87 (in Russ.).

131. Buryakov N.P., Buryakova M.A. IV International conference «Actual points for veterinary homoeopathy». St. Peterburg, 2006: 168-171.

132. Warnke P.H., Becker S.T., Podschun R., Sivananthan S., Springer I.N., Russo P.A. The battle against multi-resistant strains: renaissance of antimicrobial essential oils as a promising force to fight hospital-acquired infections. Cranio-Maxillofacial Surgery, 2009, 37(7): 392397 (doi: 10.1016/j.jcms.2009.03.017).

133. Mulyaningsih S., Sporer F., Zimmermann S., Reichling J., Wink M. Synergistic properties of the terpenoids aromadendrene and 1,8-cineole from the essential oil of Eucalyptus globulus against antibiotic-susceptible and antibiotic-resistant pathogens. Phytomedicine, 2010, 17(13): 1061-1066 (doi: 10.1016/j.phymed.2010.06.018).

134. Van Vuuren S.F., Suliman S., Viljoen A.M. The antimicrobial activity of four commercial essential oils in combination with conventional antimicrobials. Letters in Applied Microbiology, 2009, 48(4): 440-446 (doi: 10.1111/j.1472-765X.2008.02548.x).

135. Niu C., Afre S., Gilbert E.S. Subinhibitory concentrations of cinnamaldehyde interfere with quorum sensing. Letters in Applied Microbiology, 2006, 43(5): 489-494 (doi: 10.1111/J.1472765X.2006.02001.X).

136. Sarica S., Ciftci A., Demir E., Kilinc K., Yildirim Y. Use of an antibiotic growth promoter and two herbal natural feed additives with and without exogenous enzymes in wheat based broiler diets. South African Journal of Animal Science, 2005, 35(1): 61-72 (doi: 10.4314/SAJAS.V35I1.4050).

137. Markoishvili K., Tsitlanadze G., Katsarava R., Morris J.G. Jr., Sulakvelidze A. A novel sustained-release matrix based on biodegradable poly (ester amide)s and impregnated with bacteriophages and an antibiotic shows promise in management of infected venous stasis ulcers and other poorly healing wounds. International Journal of Dermatology, 2002, 41(7): 453-458 (doi: 10.1046/j.1365-4362.2002.01451.x).

138. Balaban N., Gov Y., Bitler A., Boelaert J.R. Prevention of Staphylococcus aureus biofilm on dialysis catheters and adherence to human cells. Kidney International, 2003, 63(1): 340-345 (doi: 10.1046/j.1523-1755.2003.00733.x).

139. Giacometti A., Cirioni O., Ghiselli R., Dell'Acqua G., Orlando F., D’Amato G. RNAIIIinhibiting peptide improves efficacy of clinically used antibiotics in a murine model of staphylococcal sepsis. Peptides, 2005, 26(2): 169-175 (doi: 10.1016/j.peptides.2004.09.018).

140. Starkey M., Lepine F., Maura D., Bandyopadhaya A., Lesic B., He J. Identification of antivirulence compounds that disrupt quorum-sensing regulated acute and persistent pathogenicity. PLoS Pathogens, 2014, 10(8): e1004321 (doi: 10.1371/journal.ppat.1004321). 
141. Maura D., Rahme L.G. Pharmacological inhibition of the Pseudomonas aeruginosa MvfR quorum sensing system interferes with biofilm formation and potentiates antibiotic-mediated biofilm disruption. Antimicrobial Agents and Chemotherapy, 2017, 61(12): e01362-17 (doi: 10.1128/AAC.01362-17).

142. Jakobsen T.H., van Gennip M., Phipps R.K., Shanmugham M.S., Christensen L.D., Alhede M., Skindersoe M.E., Rasmussen T.B., Friedrich K., Uthe F., Jensen P.Ø., Moser C., Nielsen K.F., Eberl L., Larsen T.O., Tanner D., Hwiby N., Bjarnsholt T., Givskov M. Ajoene, a sulfur-rich molecule from garlic, inhibits genes controlled by quorum sensing. Antimicrobial Agents and Chemotherapy, 2012, 56(5): 2314-2325 (doi: 10.1128/AAC.05919-11).

143. Stenvang M., Dueholm M.S., Vad B.S., Seviour T., Zeng G., Geifman-Shochat S. Epigallocatechin gallate remodels overexpressed functional amyloids in Pseudomonas aeruginosa and increases biofilm susceptibility to antibiotic treatment. Journal of Biological Chemistry, 2016, 291(51): 26540-26553 (doi: 10.1074/jbc.M116.739953).

144. Guo Q., Wei Y., Xia B., Jin Y., Liu C., Pan X. Identification of a small molecule that simultaneously suppresses virulence and antibiotic resistance of Pseudomonas aeruginosa. Scientific Reports, 2016, 6: 19141 (doi: 10.1038/srep19141).

145. Furiga A., Lajoie B., El Hage S., Baziard G., Roques C. Impairment of Pseudomonas aerugino$s a$ biofilm resistance to antibiotics by combining the drugs with a new quorum-sensing inhibitor. Antimicrobial Agents and Chemotherapy, 2016, 60: 1676-1686 (doi: 10.1128/AAC.02533-15).

146. Bulman Z.P., Ly N.S., Lenhard J.R., Holden P.N., Bulitta J.B., Tsuji B.T. Influence of rhlR and las $R$ on polymyxin pharmacodynamics in Pseudomonas aeruginosa and implications for quorum sensing inhibition with azithromycin. Antimicrobial Agents and Chemotherapy, 2017, 61: e00096-16 (doi: 10.1128/AAC.00096-16).

147. Das M.C., Sandhu P., Gupta P., Rudrapaul P., De U.C., Tribedi P. Attenuation of Pseudomonas aeruginosa biofilm formation by Vitexin: a combinatorial study with azithromycin and gentamicin. Scientific Reports, 2015, 6: 23347 (doi: 10.1038/srep23347).

148. Gupta P., Chhibber S., Harjai K. Efficacy of purified lactonase and ciprofloxacin in preventing systemic spread of Pseudomonas aeruginosa in murine burn wound model. Burns, 2015, 41(1): 153-162 (doi: 10.1016/j.burns.2014.06.009). 